\title{
DESTERRAR EL VICIO Y SERENAR LAS CONCIENCIAS: MENDICIDAD Y POBREZA EN LA CARACAS DEL SIGLO XVIII
}

\author{
POR \\ FRÉDÉRIQUE LANGUE \\ Centre National de la Recherche Scientifique. Paris
}

\begin{abstract}
Aludir a las "clases peligrosas" constituye hoy en día una referencia casi obligada a la historiografía del siglo XIX europeo. En realidad, esta preocupación manifestada por las élites dirigentes del momento tiene orígenes muy antiguos que el crecimiento demográfico, junto a las modificaciones que se produjeron en el reparto étnico de la población, y al espíritu de las Luces, contribuye en evidenciar. Tal es el caso en ciertas regiones de América española, especialmente en la Venezuela de fines del siglo XVIII. El control de los pobres y de los desviantes no constituye una novedad en sí -como lo demuestran los trabajos de Michel Foucault y de Jean Delumeau - en el mundo occidental, incluyendo a la Península Ibérica. En cambio, la presión que se ejerció en distintos niveles - una presión demográfica, económica, social e incluso intelectual por medio de la Universidad-(1) por las castas/pardos representa un elemento fundamental a la hora de considerar las estructuras mentales de ese estrato superior de la sociedad colonial venezolana, la aristocracia mantuana, cuyos modelos de comportamientos se adaptan precisamente a unas circunstancias locales sumamente movedizas.
\end{abstract}

Desconcertadas ante una situación fértil en rebeliones de esclavos y de pardos $-1749,1795,1797$ con la conspiración de Gual y España, en el contexto de las revoluciones americana y

SIGLAS UTILIZADAS:

AA: Archivo Arquidiocesano, Caracas.

ACM: Archivo del Consejo Municipal, Caracas.

(1) Ildefonso Leal, "La Universidad de Caracas y los pardos", Revista de Historia, Caracas, 1962, no 15, marzo de 1962, págs. 51-74. 
francesa, temiendo que se vayan a difundir las "ideas perniciosas» que desarrolló la Revolución francesa-, influenciadas por las teorias higienistas y urbanísticas de fines del siglo XVIII -las cuales transitan hay que recordarlo por la Península-, las élites locales llegaron por lo tanto a expresar a través de una serie de decisiones un conjunto de temores o de miedos, de índole escatológico, vinculadas entre sí. Es en este sentido como habría que interpretar el fenómeno de la revolución de Independencia en cuanto "guerra de clases y de castas" o también en cuanto "guerra civil»/internacional, tal como lo pusieron de relieve Laureano Vallenilla Lanz y Germán Carrera Damas (2).

Un elemento explica, por cierto, estas reacciones particularmente marcadas, que sean de tipo institucional o categorial: se expresan, en efecto, por medio de las instancias municipales, del cabildo y en todo caso, propician la intervención de las autoridades políticas locales, intendente, gobernador-capitán general, Audiencia e incluso de las autoridades eclesiásticas, el papel menor en esta parte de América con motivo de la distancia a la sede cartagenera, del Tribunal del Santo Oficio, regulador por excelencia del orden moral en otras regiones (Nueva España). Al igual que en el resto de la América española existen en Caracas varios procedimientos y lugares cuya finalidad es regular el malestar social, que sea por medio de la caridad propiamente dicha (Hospicio de la Caridad) o bien de la represión y del «encerramiento" (cárceles). Pero en las postrimerías del siglo XVH, como lo demuestra la creación de la Casa de Misericordia, establecimiento de ambiguo estatuto, a la vez refugio y cárcel, surgen preocupaciones que tienen que ver al mismo tiempo con el orden moral y social, preocupaciones particularmente significativas de un estado de espíritu: preservar la tranquilidad pública y el orden moral ya no le corresponde de manera exclusiva a una Iglesia dominada por las preocupaciones de tipo escatológico; y asimismo, los prelados tienden a intervenir en otros sectores de

(2) Jean Delumeau, La peur en Occident (XVe-XVIIIe siècles). Une cité assiégée, Paris, Fayard, 1978, passim (existe traducción española, Madrid, Taurus, 1989). Laureano Vallenilla Lanz, Obras completas, tomo I, Cesarismo democrático, Caracas, Universidad Santa María, 1983, passim, Germán CARRERA Damas, Venezuela: proyecto nacional y poder social, Barcelona, Crítica, 1986, págs. 30 y ss.; véase, para el final del período considerado la interpretación escatológica del obispo Ibarra, en nuestro trabajo "De moralista a arbitrista: Francisco de Ibarra, obispo de Venezuela (1798-1806)", Suplemento de Anuario de Estudios Americanos (Historiografía y Bibliografía Americanistas), Séville, 1992, XLIX, no 1, págs. 55-84. Federico Brito FigueroA, "Venezuela colonial: las rebeliones de esclavos y la Revolución francesa", Caravelle, n² 54, 1990, págs. 263-289. 
la vida pública, al igual que los arbitristas que se dieron a conocer en épocas anteriores.

\section{INDIGENTES Y VAGABUNDOS: UNA PREOCUPACIÓN RELIGIOSA Y MORAL}

Una de las características de la historia de América, por lo menos en la época que nos interesa aquí, es su carácter oficial. Entre los autores de los informes, de las cuentas y representaciones diversas dirigidas a los organismos metropolitanos (Consejo de Indias, Casa de Contratación, Cámara de Indias), figuran los ministros de la Corona, de manera general los representantes de ésta en las Indias, oficiales reales, eclesiásticos y representantes de las élites económicas locales. En ningún caso procede esta documentación de la gran masa de la población, cuyo acceso a la instrucción sigue siendo inexistente - salvo contadas excepciones que no se pueden identificar de todas formas antes de finales del siglo XVWI. En realidad, sólo las informaciones que proceden de los ministros del culto, especialmente las visitas pastorales y los documentos inquisitoriales -teniendo en cuenta el hecho de que los indios no están sometidos a esta jurisdicción de excepción-, los juicios criminales y civiles les permiten a «los de abajo» aparecer en el escenario americano: de hecho cuando hay, de manera u otra, ruptura o por lo menos cuestionamiento de lo que se considera como el orden establecido (pobreza de los parroquianos, comportamentos desviantes o perjudiciales con respecto a la ortodoxia moral etc. ...), lo que les confiere a determinadas visitas pastorales un papel de revelador social.

La cuestión de los pobres se suele asociar en la España imperial al fenómeno de la criminalidad. Llega a ser un tema literario muy trillado, al igual que en la casi totalidad de mundo mediterráneo de la época. El virrey de Cataluña, Hurtado de Mendoza, estigmatizaba el auge numérico de los vagos con una fórmula algo lapidaria: «Bien sabéis que soportar vagabundos en el país es criar ladrones en él». Al participar de la mentalidad dominante, según la cual es "vil» todo "oficio mecánico», en otros términos el conjunto de las actividades productivas (esta aprensión sufrirá un cambio radical sólo en 1784, durante el gobierno de Aranda), le convierte al indigente y al mendigo en un ladrón, en un salteador de caminos y de cierto modo en héroes potenciales cuyo nombre no dejaba de sorprender a los viajeros que reco- 
rrían la Península. Bajo el gobierno de los Borbones son a la vez instituciones públicas y privadas las que auxilian a los pobres y van edificando hospitales, hospicios y asilos en toda España, abriendo los conventos cuando suena la hora de cenar, amén de las numerosas casas de misericordia, de recogidas y de expósitos. En 1795 se registraban unos 2.166 establecimientos caritativos. Después de unos intentos encaminados a controlar, en períodos anteriores, la mendicidad se había llegado a un «régimen de libertad completaw. Los monarcas ilustrados contribuyeron, sin embargo, a modificar la aprensión de la situación. Floridablanca instó, por ejemplo, a Carlos III a que suprimiera la limosna que se les hacía a las hordas de mendigos que acompañaban las cazas reales y utilizara esta cantidad de dinero y los bienes de las cofradías suprimidas, así como la limosna públicas para formar Juntas de Caridad. Hasta se contempló la posibilidad de que los eclesiásticos renunciaran a dar limosnas por sí mismos y utilizaran la tercera parte de sus ingresos para crear un Fondo Pío, lo que equivalía de hecho a secularizar y organizar la caridad (3).

Remediar a la miseria de los "verdaderos" indigentes y necesitados no implicaba por eso que se olvidara a los delincuentes, ladrones y otros criminales, sometidos a la leva desde el reinado de Fernando VI, disposición que se vio reforzada por la Ordenanza de 1775. Parece ser sin embargo, que la tolerancia era más grande que en las sociedades anglosajonas del momento. El temor a las sublevaciones populares -o municipales...- seguía siendo por otra parte una preocupación constante para los políticos de la Península. Después de la sublevación de Madrid, Aranda no vacila al recordar los castigos que previene la legislación para mendigos y vagos e instituye una "comisión para los vagabundos" encargada de limpiar la capital con la ayuda de los militares y de los "ociosos» que no podían justificar de una ocupación regular. Así se iba realizando la "selección" entre delincuentes e indigentes. A éstos se les solía enviar a unos hospicios u otros establecimientos caritativos, de los cuales Olavide fue en Madrid uno de los administradores más eficientes. La institución en 1778 de los llamados alcaldes de barrio se inscribe en el marco de la racionalización de la caridad pública. Elegidos entre los vecinos «ricos

(3) Citado por J. Vicens Vives, Historia de España y América, social y económica, vol. III, Los Austrias. Imperio español en América, Barcelona, Vicens Bolsillo, 1979 (3. ${ }^{a}$ reed.), pág. 111; y vol. IV, Los Borbones. El siglo XVIII en España y América, págs. 103-104. 
y zelosos", los alcaldes a quienes asistían unos diputados, tenían a su cargo la asistencia -en lo material y lo médico- a los indigentes, siendo facilitada ésta por las recolecciones públicas. Está por demás decir que este control social corría pareja con una vigilancia no menos eficaz. Se le había otorgado poderes de policía al alcalde de barrio, tenía por lo tanto facultad para poner presos a los mendigos y vagabundos, interrogarlos e incluso llevar un registro de los infractores (4).

En la Península como en América -y a pesar de que en el Nuevo Mundo, la cuestión de los pobres nunca haya sido expresada en términos comparables, sobre todo tan radicales-, piedad y caridad se afirman como actitudes propias de las élites, antes de que se haya encontrado una solución de tipo institucional a un problema de orden social (5). Bien se conoce ahora la constancia de las élites americanas cuando se trata de demostrar su piedad, y su participación sistemática, casi obligada en las obras caritativas o también sus innumerables inversiones suntuarias (iglesias, capillas y catedrales, conventos y monasterios etc. ...). De estas acciones dependía en efecto la salvación del alma. Los Grandes de la época tenían además el valor de modelos para sus contemporáneos de menor estatuto social. A mediados del siglo XVIII, uno de los mineros más importantes, uno de los aristócratas más famosos de Zacatecas (Nueva España), el conde de Santiago de la Laguna, convidaba todos los domingos a su mesa a los pobres de la ciudad, y todos los poderosos del lugar tenían un día reservado al efecto, ésto hasta finales del siglo (6).

Un ejemplo significativo de esta mentalidad de indiscutible raigambre hispánica lo tenemos en la Venezuela del siglo XVIII con el conde de San Javier, Antonio Pacheco y Tovar: la muerte sigue siendo para las élites una oportunidad de dar limosnas y de realizar varias donaciones a favor de las instituciones caritativas. La participación directa de los pobres en las exequias tiene un carácter más inusitado, por no decir excepcional: en este caso, no fueron sus iguales, el deán de la catedral, los cabildos eclesiástico y civil o los representantes de las distintas Órdenes

(4) Bartolomé Bennassar, Historie des Espagnols XVIe-XXe siècle, Paris, Robert Laffont, 1992, págs. 607-609. C. J. RIBTON TURNER, A History of Vagrants and Vagrancy and Beggars and Begging, Monclair (NJ), Patterson Smith, 1972.

(5) Bartolomé Bennassar, Histoire des Espagnols XVIe-XXe siècle, Paris, Robert Laffont, 1992, págs. 607-609. TURNER [4].

(6) Sobre el particular, véase nuestro trabajo, Mines, terres et société à Zacatecas (Mexique) de la fin du XVIIe siècle à l'Indépendance, Paris, Publications de la Sorbonne, 1992, págs. 329-330. 
religiosas instaladas en Caracas (franciscanos, dominicos, mercedarios) los únicos en acompañarle al difunto hasta su última morada, "cargaron su cuerpo doce pobres de solemnidad sin excepción de colores y (...) a cada uno de ellos se le dieron cuatro pesos de limosnan indica el testamento establecido por los albaceas del difunto conde (7).

Esta disposición es sin lugar a dudas excepcional. Sin embargo, no fue una iniciativa aislada. En 1704, el Maestre de Campo Juan Mijares de Solórzano tenía previsto en su testamento, amén de mil misas cantadas para las almas de los Indios de su encomienda y de los esclavos desaparecidos estando a su servicio, fundar una obra pía con las siguientes características: con los réditos de los 1.000 pesos afectados a esta fundación, había que darles limosna el Viernes Santo a 25 «pobres vergonzantes" (a razón de 2 pesos por persona). El marqués volvió a insistir además en esta cláusula, esta vez a favor de otros 25 beneficiarios. La ejecución de esta voluntad le correspondía al convento de San Jacinto. La correspondiente cantidad de dinero se tenía que sacar de los bienes del marqués y de su esposa. Otra disposición tomada por el aristócrata para auxiliar a los pobres: la fundación de otra obra pía, destinada esta vez a facilitarle una dote a «alguna doncella pobre hija de gente honrada" (8).

Pero en la mayoría de los casos, la solución más cómoda y más inmediata también, consistía en encarcelar a los desviantes de todo tipo. De ahí el hecho de que existieron, para el período que nos interesa, varias categorías de establecimientos especializados. En primer lugar, las cárceles eclesiásticas, las cárceles que dependen de la jurisdicción reales (cárceles llamadas reales o de Corte) cuya construcción la dispuso la real cédula de 1687 y cuya administración le correspondió en parte a la Audiencia a partir de la creación de ésta (1786); la Casa de Corrección, destinada a los pardos y negros, hombres y mujeres, especialmente a los esclavos rebeldes; el hospicio-cárcel de las mujeres (en principio reservado a las mujeres blancas, pero encontramos numerosos casos de pardas recluidas allí con motivo de la "mala vida" que llevaban, lo que atestigua la dualidad del establecimiento, que

(7) AA, Testamentarías, 50: testamento con fecha del 25 de mayo de 1745, establecido en Caracas por Fr. Mauro de Tovar, Juan Jaciento Pacheco y Mijares (conde de San Javier), Francisco Javier Mijares de Solórzano y Domingo Antonio de Tovar.

(8) AA, Testamentarías, Anexo A: Poder para testar otorgado por el Maestro de Campo Juan Mijares de Solórzano, marqués de Mijares, Caracas, 6 de marzo de 1704; testamento del 4 de mayo de 1713. 
hacía las veces de cárcel y de hospital para mujeres, como lo indica el obispo Martí durante su visita de la diócesis); otras cárceles que dependian de las alcaldías de barrio, ligadas a la creación de esta institución en 1775 y a la extensión de la jurisdicción de Caracas; se encontraban bajo la autoridad del gobernador-capitán general le correspondía además nombrar a los referidos alcaldes; las cárceles para indígenas y finalmente cualquier lugar de reclusión que no entrara en una de estas categorias: se trataba con frecuencia de cárceles privadas, temporales (las casas de unos vecinos honestos o el mismo domicilio del reo, si éste pertenecía a la élite local) (9).

El establecimiento que nos interesa aquí no encaja realmente en ninguna de estas categorías y uno de los motivos que llevaron a su creación parece haber sido precisamente el estado de deterioro de la cárcel real en el último tercio del siglo. En todo caso, la confusión con la "casa de correción" es una de las características propias del nuevo establecimiento: no fue reservado a la protección de los «auténticos" pobres, como lo dejaba pensar su denominación inicial y las circunstancias que rodearon su creación. Esta característica constituye también un testimonio -entre otros- de la relación ambigua que se estableció en el mundo hispánico del siglo XVIII entre la noción de pobreza y la de subversión, aunque en América, se consideró a aquella bajo las especies de la delincuencia más que del banditismo organizado que se había impuesto en la Península.

\section{EL MIEDO A LA OCIOSIDAD}

De hecho, las postrimerías del siglo XVIII se caracterizan por la creciente preocupación manifestada por las autoridades y las élites locales para con los ociosos y los mendigos. Estas desviaciones, a finales de cuenta menores, son al mismo tiempo el revelador y el catalizador de unos temores escondidos y por eso mismo se les asocia - habido cuenta del auge demográfico de esta categoría étnica - a la multitud de los pardos y de la misma manera a los esclavos insurrectos o fugitivos (varias rebeliones

(9) Clasificación establecida por Ermila Troconis de VeracoecheA, en su Historia de las cárceles en Venezuela (1600-1890), Caracas, Academia Nacional de la Historia, 1983, coll. "Estudios, Monografías y Ensayos", págs. 24 y ss. Obispo Mariano MARTí, Documentos relativos a su visita pastoral de la diócesis de Caracas (1771-1784), Caracas, Academia Nacional de la Historia, 1989, tomo VI, Compendio, pág. 16. 
tienen lugar en el transcurso del siglo XVIII). El gobernadorcapitán general subraya la progresión notable de la umendicidad voluntaria" y las alteraciones del orden público que resultan de ello en estos términos:

los progresos sensibles que hace de día en día la mendicidad voluntaria, y que con un exterior artificioso en el vestido, semblante y palabras disfrazan mucho la desidia y el ocio que eligen por oficio para no tener jamás en que descansar, sino sobre una masa horrorosa de vicios, preciso objeto de la holgazanería...

De ahí la necesidad de tomar medidas adecuadas, "de suerte que los mendigos robustos no usurpen las limosnas debidas a los enfermos o impedidos por accidente, edad, o sexo, para ganar con su propio trabajo el alimento necesario". En el mismo documento, Guillelmi insistió en la urgencia que había de crear una casa-hospicio donde se pudiera recoger - pero separándolos- a hombres y mujeres de cualquier edad, sin recursos ni trabajo, que se encontraran en la necesidad de recurrir a la mendicidad. En semejante lugar podrian vivir con la decencia conveniente y dedicarse a varias tareas útiles... (10).

Consultado y debidamente solicitado - ya que fue necesaria una suscripción para llevar a cabo este proyecto- el cabildo caraqueño, bien conocido por su «infatigable caridad con los verdaderos pobres", organizó una sesión extraordinaria al efecto (1 octubre 1787). Se convocó a las personas "de distinción" de la ciudad, y se llevó a cabo esta reunión bajo la presidencia de Lorenzo de Ponte, alcalde de primer voto, y Francisco Antonio García de Quintana, alcalde de segundo voto. Como lo subrayó el gobernador y lo confirmó la junta de vecinos del 11 de octubre, no era la primera vez que se planteaba el problema. No carece de interés recordar que a esta reunión participaron todas las autoridades políticas y morales de la Provincia: el gobernadorcapitán general, el obispo de la diócesis (en aquel entonces Mariano Martí), el intendente Francisco Saavedra, el oidor regente Antonio López Quintana, Joseph Lorenzo Borges deán de la iglesia catedral, el oidor Juan Nepomuceno de Pedraza, el fiscal Julián Diáz Sarabia, y Francisco de Tocar, arcediano de la catedral.

(10) ACM, Casa de Misericordia, vol. único: auto de Guillelmi, Caracas, 1 de octubre de 1787. Salvo especificación distinta, todas las referencias a la Casa de Misericordia figuran en este legajo. 
También estuvieron presentes el alcalde de primer voto - desempeñaba el papel de juez ordinario en este asunto-, el segundo alcalde, el regidor alguacil mayor Antonio Egaña, el regidor alcalde provincial Luis Blanco y Blanco, el regidor fiel ejecutor Isidoro López Méndez, el síndico procurador Juan Bautista Echezuría y otros vecinos principales, en otros términos todas las personas a quienes preocupaban de manera u otra el problema. Cuarenta y ocho personas, incluyendo a las autoridades locales y a los representantes de las élites, firmaron esta petición de principio (11). Fue designada explícitamente como causa de la «mendicidad voluntaria" la ociosidad, calificada de "seminario de infinitos males conocidos de todos". De ahí la necesidad de separar a los verdaderos pobres de los holgazanes - una distinción que se remonta a Justiniano-:

discernir y proteger los verdaderos pobres separándolos de los holgazanes pordioseros falsos que con palabras estudiadas, semblante artificioso y traje asqueroso viven cubiertos de vicios, corrompen a los buenos, usurpan la limosna debida a los necesitados acechando las casas, roban siempre que pueden, y no tienen con que descansar sino sobre una masa de arbitrios inicuos contra la felicidad pública en cuyo supuesto es de la primera obligación de los magistrados en observancia de las leyes contener los progresos de los vagos, dirigirlos y ocuparlos de suerte que no lo sean, precaverlos para lo sucesivo y tomar medidas justas a fin de que no se confunda esta gente perjudicial con los que son verdaderamente pobres, proporcionando a éstos los auxilios que dicta la caridad sin dejar de ocuparlos según lo permita el sexo, la edad y fuerzas a cuyos objetos de tanta gravedad e influencia así por lo correspondiente al Gobierno como por la Administración de Justicia y a la seguridad de tantas personas como hay en este Pueblo, verdaderamente caritativos en la buena aplicación de las limosnas, socorros y beneficios ha estimado y estima su Señoría no sólo útil sino preciso el establecimiento de un hospicio para verdaderos pobres de ambos sexos en el cual sean socorridos y al mismo tiempo en la forma insinuada, aplicados y dirigidos sobre buenas costumbres, interin por otra parte los falsos pobres o mendigos robustos voluntarios quedan descubiertos y en precisión de ocuparse o ser destinados por la autoridad pública para ganar con su sudor el sustento como es justo...

(11) El marqués del Valle de Santiago, Juan Javier Mijares de Solórzano, Ignacio Xedler, Juan de Iriarte, Manuel Felipe de Tovar, Santiago Ponte y Mijares, entre otros representantes de las familias mantuanas. ACM, Actas del Cabildo, 1787: fo 203 y ss. (1 y 11 de octubre de 1787). 
En esta perspectiva se decidió la creación de una «junta de dirección del hospicion a la que se le encargó encontrar un terreno, dirigir la construcción del hospicio -o la refección del mismo- y de señalar a las personas encargadas de las operaciones. Se le pidió al obispo que concurra a la referida junta de dirección del hospicio como «verdadero padre de los pobres necesitados, repartiendo con mano liberalísima el más ardiente zelo ejemplar todas sus rentas en socorrerlos". Al «protector señalado de los verdaderos pobres" se le consideraba como el "fundamento más seguro de esta gran obra" que de entrada, se caracteriza en mayor grado por su vocación caritativa que propiamente redentora (12). Estos primeros pasos no les eximían a los inspiradores de la empresa que buscaran fondos suficientes (estimados en 4.911 pesos 11 reales) como para remediar a mayor brevedad a los «males" de la ciudad. Se decidió entonces establecer «listas de donativos por parroquias" así como por cuerpos/profesiones. Al poco tiempo (1788) se planteó el problema de la elección del terreno ubicado - con sus casas- junto al río Anauco, en la parroquia de Candelaria, la refección del edificio (compra de cal y piedra) y la elaboración de los planes: o sea un lugar de fácil acceso, cercano al hospicio que estaban construyendo precisamente los Capuchinos y por lo tanto de la «asistencia espiritual» que les pudieran proporcionar éstos padres, inmediato también al río Guaire, y al futuro cuartel de milicias. Se descartó al otro sitio (barrio de la Santísima Trinidad) por resultar más caro llevar agua hasta alli. De hecho, fue la escasez de terrenos comunales la que les obligó a los interesados a que buscaran un sitio más adecuado (13).

Al año, ya se va notando una evolución a favor de la refor-

(12) Junto al obispo figuraban el Intendente, el Regente, el fiscal Julián Díaz de Sarabia, el chantre de la cathedral Dr. Francisco Ibarra, el Dr. Pedro Martínez, el primer alcalde Lorenzo de Ponte, Joseph de Escorihuela (se le nombró tesorero), el teniente del Rey Pedro de Nava, Joseph Cocho de Iriarte (capitán de milicias de los Valles de Aragua), Manuel Felipe de Tovar, Joseph Domingo Blanco, Juan Joseph Mintegui (contador de esta "obra pia") el teniente coronal Ricardo Mead et Francisco Xavier de Longa (junta del 29 de octubre de 1787).

(13) La distribución de los cuartos es reveladora de las preocupaciones de la junta, y en especial del lugar que se les asignó a las mujeres en esta casa: "viviendas del capellán, del administrador general, dormitorio, enfermería, reclusión, sala de impedidas, otro de manufacturas, cocina, refectorio, despensa, pieza para desmontar, otra para hilar, otra para tejer, otra para coser, lavadero con baño, lugares comunes, pieza para secar, cuarto de contagiosas, otro de locas..." (agosto de 1788). El presupuesto era de 1.204 pesos 4 reales en noviembre 1788 . Se evaluó la casa existente en 1.970 pesos 4 reales (fundaciones). Véase también ACM, Actas del Cabildo, 1788: sesiones del 22 y 30 de septiembre de 1788, y del 23 de noviembre de 1788 . 
mación de las costumbres incriminadas. La junta que se reúne en septiembre de 1788 indica que la casa "ha de servir a la corrección y dirección de las costumbres», lo que requiere que el lugar elegido quede algo aislado, «separado del público» y con "menos proporciones para la distracción». Asimismo se insiste en el hecho de que tiene que ha de ser un lugar bien ventilado (para los enfermos). Un mes después, se evoca la creación de una "división de incorregibles", y luego de una división reservada a los niños expósitos que serían numerosos no sólo en la capital sino también en el resto de la Provincia (14).

La unanimidad realmente excepcional que prevaleció hasta entonces empezó, sin embargo, a resquebrajarse cuando se llegó al capítulo material del proyecto. Pese a la petición formulada por la junta, el cabildo se mostró renuente a utilizar los propios y las rentas que proporcionaban los mismos para adquirir el solar y las casas adyacentes, por más que estuviera llena la cárcel pública que lindaba con las salas capitulares y las moradas de las élites locales. Los capitulares dijeron temer el control total que resultaría en este caso a favor de la Junta Suprema de Real Hacienda. Además, se le presentaba en el mismo momento otro problema, el de la dotación de la Escuela de primeras letras (que contempla el art. 34 de la Ordenanza de Intendentes) (15).

Para septiembre de 1789, ya estaba concluida la casa destinada al «recogimiento de los pobres». En consecuencia, la junta le pidió un bando al Presidente de la Audiencia para que se anuncie la apertura de la misma. Fue nombrada rectora Juana Yánes ("de calidad blanca») y como médico se eligió a Juan Pedro Barceló. El Dr. Pedro Manuel Yépez, cura de la parroquia de Candelaria, asistiría a los pobres, aunque el obispo Ibarra se negó a que estuviera afectado de manera permanente un cura en la Casa de Misericordia, manifestando que no se podría sufragar semejante gasto. Una "multitud de mujeres pobres" ya había acudido a las puertas del palacio episcopal para recoger la acostumbrada limosna de dos reales que el obispo les repartía los sábados. Convencidos de que el obispo tenía poco interés e incluso mostraba "repugnancia» por la casa, los vocales se apresuraron en denunciar la "distribución de las rentas por limosnas" tal

(14) Juntas del 28 de septiembre y 4 de octubre de 1788, Caracas.

(15) Junta del 9 de noviembre de 1788; cabildo extraordinario de 23 de noviembre de 1788. La Junta de misericordia se conformó por lo tanto con utilizar sus fondos propios y recurrir a la piedad de los vecinos de Caracas (junta de 23 de noviembre de 1788). 
como la practicaba el prelado, indicando que los beneficiarios corrían a las guaraperias "a emplear lo que habían cogido»:

y en otros vicios que por lo general se amontonan sobre semejantes pobres que, no teniendo por toda su vida el menor rubor de presentarse en las calles, plazas y puertas al medio día, como a la media noche, para pedir limosna, se han convertido de pronto en figura de vergonzantes, y establecido el método de usurpar aquella limosna por medio de memoriales para continuar en la ociosidad, abandono y vicios consiguientes (16).

En realidad, la iglesia estaba convencida que, de aceptar esta participación directa en esta obra caritativa, perdería buena parte del control social y espiritual que ejercía tradicionalmente en los parroquianos. El obispo consideraba además que, por ser destinada a las mujeres (¿en prioridad?), el gobierno de la Casa de Misericordia le correspondía, actitud que indujo uno de estos numerosos conflictos jurisdiccionales propios de los territorios de ultramar. En cuanto al Intendente (Saavedra), indicó que la autoridad civil sí le correspondía a él. En ausencia del obispo, la Casa empezó a recoger a los numerosos pobres que se presentaron con exclusión sin embargo de los esclavos fugitivos. De ahí la necesidad de organizar la recolección de limosnas y más cuando los deanes de la Catedral se habían negado también a "prestar" los caudales reclamados (4.000 pesos): 16 alcancías de latón que llevaban el rótulo de Misericordia, con candado y llave, fueron entregadas a los diputados de la junta directiva, que le instó al Gobernador para que autorizara un empréstito en la extracción de los cueros de la Provincia (17).

No por eso se había zanjado la polémica relativa al financiamiento de un establecimiento que se presentó al mismo tiempo como una empresa caritativa y una casa de corrección, y en todo caso como una garantía para la conservación del orden público, y ... de la imagen de la ciudad por los vecinos. La rivalidad creada entre la institución civil y la eclesiástica explica en gran medida las dificultades y los retrasos que experimentó la obra. Y más cuando era imprescindible que la Junta de Misericordia siguiera adquiriendo bienes diversos para realizar sus fines. En diciembre de 1790, adquiere - representada por Mánual Felipe de Tovar- los bienes del difunto Juan Bautista de Eche-

(16) Junta del 27 de septiembre de 1789.

(17) Ídem, 14 de marzo y 24 de mayo de 1790. 
verria (Español europeo) o sea un solar y una casa evaluados en 577 pesos, ubicados en la Candelaria y gravados por una capellanía de 240 pesos (principal), evaluación a la que había que sumar los gastos de refección del lugar o sea 312 pesos 2 reales. Surgió un problema conexo, el de la "casa de corrección para hombres". Hasta enero de 1791, este establecimiento funcionó en una casa perteneciente a un tal Juan Hernández Grillo. Pero el juicio entablado contra éste ante la Audiencia por Juana Josefa Fernández como albacea de su marido Ángel Martín tuvo como consecuencia el secuestro de la referida casa. De ahí la necesidad para la Junta de adquirirla a mayor brevedad y las reiteradas peticiones que formuló al efecto ante el gobernador para beneficiar de las rentas de determinados rubros fiscales (18).

Entre los huéspedes involuntarios de la casa estaban los expósitos, que llegaron a constituir otra preocupación mayor en la Caracas de fines del siglo. El proyecto de creación de un establecimiento especializado sólo se concretizará sin embargo en 1820. Alli encontraron los miembros de la Junta de Misericordia otro argumento de que valerse en la búsqueda de fondos: la "muerte de los niños botados en los zaguanes y puertas de la calle sin el agua del Santo Bautizo y algunos destrozados de los animales". La aprobación oficial de la creación de la Casa, por medio de la real cédula de 15 de junio de 1791, puso un término provisional a la polémica que se había instaurado acerca del financiamiento de la Casa. El texto retoma en todo caso el análisis hecho por los promotores del proyecto: entre los males que asolan la capital caraqueña figura en debido lugar la "falta de educación» y no solamente la «mendicidad voluntaria». Tratándose de una situación propia de las mujeres, resultaba urgente corregir el mal por la raíz, rectificando las costumbres de las mujeres pobres $u$ holgazanas en la nueva Casa. Esta "reeducación» se fundaba en el trabajo: «aplicándolas a demotar, hilar, tejer, beneficiar el algodón, y otras cosas capaces de sostener en gran parte la misma casa». 24 tornos se reservaron para las mujeres que "por ser blancas, tenían por bajeza la ocupación que debería honrarlas» (19).

En las condiciones algo contradictorias que acompañaron la

(18) Ídem, 30 de enero y 22 de mayo de 1791. Entre las personas implicadas en este conflicto figura el maestro de escuela Domingo Hermoso de Mendoza, a quien le tocó un censo de 2.000 pesos. El interesado efectuó una donación a favor de la Casa de Misericordia.

(19) Real Cédula, Aranjuezz, 15 de junio de 1791. ACM, Actas del Cabildo: 21 de junio de 1820. 
fundación de esta obra de caridad, no es inútil recordar la lista de los integrantes de la Junta de Misericordia. Eran miembros de ella los representantes de las élites caraqueñas, tanto de las élites principales (mantuanos) que usecundarias" (caracterizadas por un menor nivel de riqueza pero presentes de la misma manera en las instancias del poder económico y político local). Entre los primeros, Manuel Felipe de Tovar, Lorenzo de Ponte, el marqués de Mijares, los condes de Tovar y de San Javier, el marqués del Valle de Santiago etc. ... con quienes nos volveremos a encontrar en la lista de los bienhechores de la Casa de Misericordia. No por casualidad se eligieron las personas encargadas de redactar las ordenanzas de la Casa en el seno de estas élites: Joseph Ignacio Moreno y Feliciano Palacios y Sojo, siendo nombrado administrador Francisco Xavier de Longa (20).

\section{BENEFICENCIA Y FINANCIAMIENTO DEL PROYECTO: PODEROSO CABALLERO ES DON DINERO}

Ante una situación tan apremiante, siguieron las donaciones y contribuciones fiscales en la orden del día. La distinguida junta no vaciló en proponer varios expedientes al efecto, así por ejemplo la organización de diversiones públicas, "nada perjudiciables al públicon como lo fueron las quince corridas de novillos en las tardes de los días festivos o también la rifa de 6.000 pesos en plata efectiva, cada tres meses "en alivio y subsistencia de la Casa, aprovechándose ella en cada rifa de la cantidad de 90

(20) "Nómina de los Señores vocales de la Junta de Misericordia: Joseph Ignacio Moreno, Feliciano Sojo, Juan Joseph Mintegui, Manuel Felipe de Tovar, Lorenzo de Ponte, Marqués de Mijares, Conde de Tovar, Conde de San Javier, Marqués del Valle de Santigo, el Fiscal, el Cura de la Catedral, Joseph Escorihuela, Pedro de Nava (Teniente del Rey), Joseph de Cocho, Joseph Domingo Blanco, el chantre Francisco de Ibarra, el contador Joseph de Vidaondo, Francisco Xavier de Longa, Santiago de Ponte, Diego Blanco, Fernando Ascanio, Isidoro Méndez, Manuel de Francia, Esteban de León, Domingo Briceño, Juan Blanco y Plaza, Carlos de Ayera, Baltasar Muñoz, Fernando Blanco y Mijares, Joseph María Muñoz, Miguel de Ponte, el Presidente Gobernador General, el Obispo, el Regente (Antonio López Quintana), el síndico procurador general, Pedro Manuel Porras, Juan Nepomuceno de Pedroza, el teniente de gobernador-auditor de guerra, Luis Antonio Méndez Quiñones, Juan Esteban Echezuria, el Intendente de Ejército y Real Hacienda, Antonio Fernández de León, Marqués del Toro, Manuel de Montserrate, Andrés de Ibarra, Diego Garate, Domingo Zulucta, Fernando Blanco y, Mijares, Antonio Rengifo, Luis Rivas, Juan Joseph Echenique, Ignacio Rengifo..." (1790). Nombramiento de J. I. Moreno y F. Palacios en la junta del 24 de septiembre de 1791. Y de F. X. de Longa, para lo que iba del año 1791 y 1792 (junta del 16 de octubre de 1791). 
pesos (cada boleto tenía un valor de 2 pesos). No se autorizaron sin embargo las loterías organizadas por particulares. Hasta al juego, ese vicio estigmatizado con constancia y obstinación por las autoridades civiles y religiosas, se le presentó como una fuente - potencial- de ingresos: le agradecería a la Junta que los juegos de envite permitidos por la legislación (trucos y villares, tambores prusianos, bochas etc. ...) contribuyeran mensualmente al mantenimiento de la Casa, esto bajo los auspicios del gobernador-capitán general y controlando por supuesto lo que se seguía considerando como lugares de perdición (21).

Otros lugares de «mal vivir» que los defensores del proyecto consideran en adelante con una mirada distinta: las célebres pulperías y tabernas. Como lo dispone el decreto del capitán general con fecha del 22 de diciembre de 1791, que funda realmente la Casa, cada pulpería próxima a establecerse en Caracas y en La Guaira tendría que abonar un derecho de 25 pesos anuales. Asimismo, la apertura de nuevas tiendas, solicitada constantemente por los mercaderes a principios de cada año, permitiría cobrarles a los interesados un peso por tienda. En el campo de la fiscalidad, se cobraría un impuesto sobre el tabaco, o sea medio real por arroba de tabaco de fumar que entrara en la ciudad. Un impuesto de medio real de plata se exigiría también por cada mula que entraría - vacía o cargada - en Caracas: era el derecho de portazgo, algo olvidado para aquel entonces pero restablecido cuando lo requerían las circunstancias (reales cédulas de 1733 y 1734). Controlar los movimientos, como lo implicaba esta decisión, hacía necesaria la construcción de dos puentes en los arroyos Catuche y Caruata, por donde se abastecía a la ciudad de toda la provincia. Otro rubro afectado por estas decisiones: la venta de ganado. El ayuntamiento nombraría dos cobradores al efecto, para efectuar controles diarios en los mencionados puentes para percibir el expresado derecho, llevando la cuenta por semana (medio real de plata por cada cuatro cabezas de ganado vacuno o caballerías mayores o menores). Unas garitas se podían establecer en otros puntos de entrada a la ciudad para verificar el asunto. Asimismo se cobraría un nuevo impuesto sobre la leña. En cuanto a las esclavas y mulatas verduleras, fruteras y pescadoras instaladas en la plaza principal, tendrían

(21) Junta del 1 de noviembre de 1791 y 28 de octubre de 1793, 21 de diciembre de 1794: la Junta solicitaba en especial que los 6 pesos mensuales que se les abonaba a los sargentos mayores en el rubro "juegos" se le atribuyeran a la Casa. Sobre este punto, véase la síntesis reciente de Angel LóPEZ CaNTOS, Juegos, fiestas y diversiones en la América española, Madrid, Mapfre, 1992, págs. 276 y ss. 
que abonar unos 6 pesos anuales. En realidad, y si consideramos la legislación anterior (real cédula 26 agosto 1733), no hay nada verdaderamente novedoso en estas medidas. Sólo atestiguan la recrudescencia de determinados problemas relacionados con el orden público (22).

Más inusitado pero no por eso menos significativo de las permanencias señaladas es el recurso hecho por la Junta de Misericordia a unos impuestos originales por lo que es de su principio, y de indudable origen peninsular. Tal es el caso de la «moderada pensión" que se les quería imponer a los vecinos que tenian fuentes en sus casas (a excepción de las casa religiosas, porque ya contribuian para el establecimiento sobre las fábricas de sebo, jabón y otros ramos) (23).

En el mismo orden de ideas, se solicitó a la Junta de sínodos para que parte de las cantidades que se les señalaban a los tenientes de cura y clérigos auxiliares de parroquias caraqueñas le correspondan en adelante a los capellanes de la Casa. Hasta a los boticarios se les pidió facilitar medicinas con regularidad. A partir del mes de marzo de 1794 se dispuso la visita de las parroquias por dos representantes de la Casa, con el fin de solicitar a las personas capaces de contribuir mensualmente en el mantenimiento del establecimiento. En el mismo momento se decidió que a toda mujer o niña a la cual se le sorprendería pidiendo limosna, se le llevaría automáticamente a la Casa de Misericordia (esto a partir del 1 de febrero de 1795). Esta empresa de beneficiencia fue sin embargo selectiva: los forasteros tendrían que regresarse a su lugar de origen, por ser demasiado importante esta categoría de pobres («inundan» Caracas). Para aquella fecha, los gastos de la Casa (comida de los huéspedes fundamentalmente) ascendían a unos 120/140 pesos mensuales (24). En 1795 , las diversiones públicas llegaron a ser incluso una fuente de ingresos considerable: el administrador Francisco Xavier de Longa recogió ese año 500 pesos gracias a los permisos que se concedieron para los espectáculos de volatines, 154 pesos 4 reales provenientes de la Casa de Comedia, otros 500 pesos para las corridas etc. ... Hay que recordar sin embargo que una de las 1791.

(22) Junta del 12 de enero de 1791; decreto de Guillelmi, 22 de diciembre de

(23) Oficio del regente, 5 de marzo de 1792: retoma una real cédula del 14 de octubre de 1733 .

(24) Junta del 18 de febrero de 1792 y 12 de marzo, 21 de diciembre de 1794. Cuentas de 1790 y 1791 . Relación de los gastos formada por la rectora Juana Yañes (1794). 
fuentes de ingresos más seguras para este tipo de fundaciones eran los censos que grababan las haciendas de la Provincia (25).

\section{URBANISMO Y ORDEN SOCIAL: EL ESPÍRITU DEL MOMENTO}

En adelante, el carácter marcadamente coactivo del recogimiento de los pobres o de su devolución a su provincia de origen se fue extendiendo a las modalidades del trabajo que se les impuso a los mismos: a las mujeres se les destinó a los «obrajes» que funcionaban dentro de la Casa, a los hombres válidos a las obras de utilidad pública y a los demás a diversas tareas que se podían efectuar dentro de la Casa, por más que se "hospedaran" en la Casa de Corrección. Tenemos un testimonio inequívoco de esta evolución con el decreto que publicó con fecha de 22 de diciembre de 1791 el gobernador-capitán general, Juan Guillelmi. Es interesante señalar que este texto retoma varias reales cédulas como por ejemplo la de 1737. En 1795, a los pocos años de su fundación, la Casa de Misericordia se afirma entonces por su vocación doble, a la vez caritativa, educativa y no exclusivamente represiva, ya que esta función le corresponde en derecho a la llamada Casa de Corrección. En todo caso, los defensores de la Casa de Misericordia mostraron poco interés en que se cerrara ese otro establecimiento - como se planteó a fines del año 1791-, por ser éste parte integrante de un dispositivo de control social. El cabildo contribuyó incluso a su mantenimiento, al destinarle unos 200 pesos sacados de los fondos de propios para alimentos de los esclavos (26). No por eso se renunció a los imperativos de caridad y bondad cristiana. En los gastos de la Casa de Misericordia figuran varios rubros adicionales: así el vino destinado a las mujeres enfermas, los cuidados a los enfermos (sacar muelas); o sobre todo el tabaco. En este sentido la Casa de Misericordia caraqueña se diferencia sin lugar a dudas de los otros establecimientos, más estrictos en sus reglamentos internos. Parece además que se les fue reservando poco a poco a las mujeres. Resulta significativo al respecto, que la confusión que existía en cuanto a la denominación de la Casa —desempeña también un papel de hospital - tuvo como consecuencia el siguiente hecho: cuando en julio de 1794, el obispo Viana tiene que nombrar a un administrador de la Casa (fue Miguel Méndez, vecino de Caracas),

(25) Acta de la Junta de Caridad, 13 de mayo de 1796. ACM, Hospitales, 1778-1825: varios ejemplos de censos, que oscilan de 500 a 2.000 pesos a principios del siglo XIX.

(26) Junta del 22 de diciembre de 1791 y 21 de diciembre de 1794. 
alude en efecto a la "Casa de recogimiento y hospital de mujeres de esta ciudad.....

Esta indecisión no resulta tan sorpresiva. Bronislaw Geremek señala en efecto que «... aparte de su génesis y del carácter de su fundación, los hospitales como asilos y lugares de distribución de limosnas eran instituciones colectivas de la beneficiencia urbana", aunque las vías por las cuales se manifestó esta misma evolucionaron bastante, contemplando en especial la intervención directa de las autoridades municipales. Dos años después, se menciona sin embargo, aunque sin insistir demasiado en el asunto, en la construcción de "una casa para recoger los hombres pobres pero sin enfermerían ya que existían los hospitales de San Pablo y de San Lázaro cuyos ingresos provenían por lo esencial de los censos que les estaban afectados (27).

Pero el carácter de la Casa/Cárcel de Corrección, en cuanto establecimiento de tipo carceral, implicaba que los presos participaran en obras de utilidad pública. Estos mismos constituían además la condición sine qua non de la existencia de la Casa. En varias oportunidades, las autoridades políticas y eclesiásticas de la Provincia así como los responsables de estos establecimientos, por ejemplo el alcaide de la Cárcel de Corrección, lamentan la falta de fondos necesarios para el funcionamiento de las cárceles (6.000 pesos), a la par que celebraban las virtudes redentoras del trabajo, especialmente para los "ociosos, vagos y mal entretenidos libres y esclavos casi siempre a queja de sus dueños o de los padres y madres de familia para corregirlos según el mérito de cada uno y rectificar sus costumbres empezadas a viciar». La noche anterior, los alcaides de cárcel habían arrestado a doce jóvenes libres y esclavos «que se hallaron jugando juegos prohibidos". De ahí la necesidad de proseguir con estos trabajos de utilidad pública, trayendo piedras para la construcción de una nueva Casa o mejorando los caminos y puentes, como el camino que unía Caracas al puerto de La Guaira.

De ahí también las dificultades con que se enfrentó el cabildo para financiar estos dos establecimientos y las medidas que pro-

(27) El administrador Miguel Méndez al Provisor Vicario General, 7 de julio de 1794. Junta de Caridad, 13 de mayo de 1796. ACM, Hospital de San Pablo, 1778-1800 y 1793-1802: a partir de 1786 se encuentran varios ejemplos de réditos, y por lo tanto de censos impuestos en las haciendas de los Valles de Caracas. Estos censos ascienden a 300, 650, 1.270, y 1.000 pesos. Escritura de reconocimiento de censo por María Bolivar, vecina de Caracas y Fernando Lovera, Fiador, de un censo impuesto en una hacienda del valle de Morón (1.000 pesos) a favor del mencionado hospital, Caracas, 7 de septiembre de 1772. Bronislaw GeremeK, Les marginaux parisiens aux XIVe et XVe siècles, Paris, Champs Flammarion, 1976, pág. 212. 
pusieron al efecto los miembros de la ilustre congregación: que los dueños de esclavos -especialmente los mantuanos, numerosos en privilegiar esta solución para los esclavos rebeldes como lo indican en sus recriminaciones contra las rochelas y otras formas de rebeliones- se encarguen de mantener a éstos. En 1795, Juan Miguel Echezuria entrega 3 pesos «reales en concepto de la manutención de un esclavo, y se señalan otros cinco casos para ese año". Asimismo pidieron que se afectara a los reos a unas obras tan urgentes como lo eran la construcción del camino de La Vega, del puente sobre el Anauco y del camino a La Guaira. En 1795, se registraban unos 33/35 esclavos en la mencionada Casa, por unos $18 / 20$ reos «libres».

Hay que precisar sin embargo que estas otras fueron objeto de un convenio entre los arrieros que recorrian los mencionados caminos y el Gobernador. Los arrieros aceptaron tomar a su cargo esta construcción por medio de su obligado Juan Joseph Alvarado. En otros términos, no le correspondía al cabildo intervenir más en este particular: ya había participado en el financiamiento de esta empresa (sacando anualmente 100 pesos de los propios) e invocaba precisamente la falta de recursos (propios) y las deudas contraídas a favor de la Real Hacienda. Además, aunque se terminó de construir en agosto de 1792, la Casa de Misericordia experimentaba algunas dificultades: varias paredes se habían derrumbado por un vicio de construcción que habían contribuido en evidenciar las abundantes lluvias. Por lo tanto, para 1793 el cabildo seguía contribuyendo en esta empresa caritativa, por más que el Gobernador haya adquirido cierto control en el asunto. Lo que lo llevó a proponer, a los tres años, varios arbitrios para solucionar el problema del financiamiento de la Casa: entre ellas, la utilización de parte de los réditos provenientes de dos obras pías, la de Chuao y la de Cata (lo sobrante del líquido), así como la libre disposición de los bienes mostrencos a favor de la Casa de Misericordia (28).

(28) En cuanto a las rebeliones de escalvos, véase las apreciaciones hechas por los cabildantes en: ACM, Actas del Cabildo, 1764-1765: sesión del 8 de octubre de 1764. Más explícitas todavía son las referencias a la sublevación de 1749, Actas, 1750: sesión del 20 de abril de 1750. Auto del Presidente de la Audiencia, Caracas, 28 de abril de 1792. Junta del Cabildo, 30 de abril de 1792 y 18 de febrero de 1793. El síndico procurador al Gobernador, 5 de mayo de 1792 . El cabildo había contribuido con 1.200 pesos en la construcción de la Casa de Corrección, cantidad a la que había que sumar 200 pesos para el mantenimiento de los reos. Francisco Javier de Longa au Gouverneur, 16 de abril de 1793. Cuentas de la Casa de Corrección, 1795. Carbonell a la Junta de la Casa de Misericordia, 27 de mayo de 1796. Sobre el particular, véase el testamento de Catalina de Mejía (1669), y el codicilio del 22 de julio de 1671 en La obra pía de Chuao 1568-1925, Caracas, UCV, 1968, págs. 194 y ss. 
PARTICIPACIÓN DE LAS ÉLITES ADMINISTRATIVAS Y ECONÓMICAS

"Razón de las cantidades que han contribuido graciosamente para la Casa de Misericordia varios individuos"

$\begin{array}{lrc}\text { Presidente Carbonell } & 50 & \text { pesos } \\ \text { Regente Antonio Quintana } & 40 & " \\ \text { Intendente Esteban Fernández de León } & 100 & " \\ \text { Fiscal de la Audiencia, Julián de Sarabia } & 30 & " \\ \text { Contador mayor, Carlos Ayerdi } & 24 & " \\ \text { Conde de Tovar } & 50 & " \\ \text { Luis de Ribas } & 50 & " \\ \text { Manuel Felipe Tovar } & 50 & " \\ \text { Isidoro López Méndez } & 60 & " \\ \text { Manuel Montserrate } & 12 & " \\ \text { Juan Blanco y Plaza } & 2 & " \\ \text { Juan Esteban Echezuria } & 80 & " \\ \text { José Ignacio Moreno } & 100 & " \\ \text { Ignacio Rengifo } & 50 & " \\ \text { Domingo Zulueta } & 50 & \\ \text { Francisco Ignacio Serrano } & 25 & " \\ \text { Juan José Echenique } & 100 & " \\ \text { Luis López Méndez } & 100 & \end{array}$

Cuentas llevadas por Luis López Méndez, 24 noviembre 1796

De ahí la importancia que adquiere, en ese contexto de crisis financiera y de tergiversaciones que la participación de las élites locales no logra subsanar, el memorial dirigido por el obispo Ibarra a los cabildos civil y eclesiástico, a los religiosos y a «todos los cuerpos y estados y a toda clase de personas de esta ciudad", a favor de los pobres de la Casa llamada aquí de "caridad». El prelado tomó esta iniciativa fundándose en su cualidad de miembro de la Junta de Caridad y retomando los argumentos desarrollados precisamente cuando se decidió la creación de la Casa (ayudar a los indigentes y castigar a los falsos mendigos) (29). El problema medular de este texto, que se presenta como una defensa explícita de la Casa y un requerimiento no radica en la relajación de las costumbres, estigmatizadas en otras oportunidades por el prelado, sino en la responsabilidad que se deriva del proyecto y de la eficiencia que adquiere en esta perspectiva la organización - a diferencia de la dispersión que prevalecía hasta

(29) "Exhortación y memorial que como pastor y como miembro de la Junta de Caridad, presenta el obispo a los Ilustres Cabildos, Sagradas Religiones, a todos los cuerpos y estados, y a toda clase de personas de esta ciudad, a favor de los pobres de la Casa de Caridad establecida en ella". Caracas, 11 de marzo de 1794. 
entonces- de la caridad: ¿Les corresponde verdaderamente a las autoridades civiles, practicar la caridad - virtud cristiana-, favorecer la redención y la educación de las clases potencialmente peligrosas, consideradas por la Iglesia como propias de su misión terrenal? A esta pregunta fundamental sólo se le iba a contestar en el transcurso del siglo XIX, como lo demuestra la situación de los hospitales y de las obras caritativas en vísperas de la Independencia $y$, de manera más general, el funcionamiento de la justicia, ya sea eclesiástica, o bien civil.

Otras medidas, como la división de la ciudad de Caracas en cuarteles (otro tanto sucedió en varias ciudades de América), la creación de los alcaldes de barrio, elegidos por sus iguales, la importancia creciente que se les concedió a las milicias urbanas encabezadas por los aristócratas locales, van mucho más allá de la perspectiva caritativa adoptada por las autoridades religiosas, por más que éstas ostenten otro tipo de preocupaciones; así como por ejemplo, la preocupación higienista. En su Memorial, el obispo Ibarra subrayaba que "la peste es hija del hambre" y que las enfermedades contagiosas (la lepra y el mal de San Antón) tenían mucho que ver con la falta de higiene, la suciedad de los cuerpos y de las almas y afectaban en mayor grado a los seres abandonados. Como lo indica A. Farge en un contexto algo distinto y en todo caso más radical, el de París en la primera mitad del siglo XVIII, "se llegó a abandonar la moral de la asistencia para preocuparse uno del orden y de la salud de los pueblos. Por eso se empezó a reflexionar acerca del espacio urbano y de la organización del mismon. Esta preocupación nueva tuvo como consecuencia unas acciones puntuales (masacres de perros en 1794, la prohibición que se dejara a los puercos en las calles, la captura de cualquier animal sin dueño) pero también el proyecto de creación de un hospital general, que defendió sin rodeos el Intendente Basadre en 1809. Hasta se planteó lo oportunidad de adquirir al efecto y con fondos públicos el antiguo cuartel de San Carlos. El hecho fue que la multiplicación de las epidemias había puesto de relieve el peligro que encerraba para la colectividad la concentración de esos grupos de indigentes, y facilitado la toma de conciencia de la necesidad de una reforma global de asistencia social.

En el mismo orden de ideas cabría señalar la relación que el cabildo caraqueño estableció entre la salubridad pública y los comportamientos reprehensibles: la inadecuación de las infraestructuras, de las vías de comunicación, de los puentes, de las 
tomas de agua etc. ... originaria en parte la ociosidad de las clases populares, así en el barrio de la Candelaria, considerado por los cabildantes como potencialmente "peligroso". De ahí la necesidad de realizar estas obras de utilidad pública (30). De ahí también varios textos y realizaciones relacionadas con esta problemática: lo que importa ahora ya no es el control de las almas sino el de los individuos, o sea el orden social, como lo indica claramente el Bando de Buen Gobierno promulgado en 1787: "no [hay que] consentir que los vecinos estantes y habitantes vivan holgazanes y sin honestos entretenimientos\%...

En esta perspectiva algo moralizadora, no se toleraba la presencia de las mujeres y de los mendigos (verdaderos o falsos) en las tabernas y otras pulperías. Hay que recordar en este sentido que un texto oficial, la real cédula de 27 de mayo de 1797, que dispone el arresto de las personas que se dedican al vicio, a la ociosidad, al juego y frecuentan las "guaraperías" y otras diversiones perniciosas para el orden público, constituía un antecedente notable para en adelante, facilitar la encarcelación de los desviantes de todo tipo y su utilización en obras de utilidad pública.

En 1807, el procurador encargado de los "pobres encarcelados" se queja ante el capitán general que eran insuficientes las cantidades de que disponía la Cárcel Real (reservada en principio a los blancos, mientras la llamada Cárcel de Corrección les servía de lugar de reclusión a los pardos y esclavos), incluso teniendo en cuenta las limosnas (el cabildo contribuía sin embargo con 30 pesos, los vecinos con 50, los diputados de llanos con 24) ya que los gastos diarios ascendían a 7 pesos. En esa oportunidad, el Capitán General Vicente Emparán volvió a afirmar que el mantenimiento de la Cárcel les correspondía a las autoridades civiles y no a los particulares, como lo había autorizado su predecesor. Algunas excepciones sin embargo: los pulperos tenían que pagar un impuesto a favor de la Cárcel de Corrección administrada bajo el control del gobernador, como lo indica la representación de 139 pulperos: tenían que abonar entre 3 y 16 pesos mensuales (los gastos de la Cárcel equivalían a los de la Casa de Misericordia,

(30) ACM, Hospitales, 1778-1825: Vicente Basadre al alcalde de primera elección, Caracas, 19 septiembre de 1809. ACM, Actas del Cabildo, 1786: cabildo extraordinario, 8 de abril de 1786. ACM, Actas del Cabildo, 1793, 1794: junta ordinaria del 28 de febrero de 1793 y 21 de enero de 1794. Arlette FARGE, Vivre dans la rue à Paris au XVIIIe siècle, Paris, Archives Gallimard, 1979, págs. 194 y ss. B. GEREMEK, La potence et la pitié. L'Europe et les pauvres du Moyen Age à nos jours, Paris, Gallimard, 1986, pág. 169. 
o sea unos 130/140 pesos mensuales). En 1809, un decreto de Emparán, aprobado por el cabildo, no dejó de confirmar el cobro de este impuesto en los comestibles a favor de los pobres encarcelados, fundándose en la "costumbre" que existía al respecto entre los vendedores. A pesar de estas medidas, era insuficiente esta cárcel y el mismo año, varios reos fueron remitidos al cuartel de San Carlos (31).

El bando de 1806 y varias ordenanzas (así las de Sanz en 1802, que fueron redactadas a petición de la Audiencia), la creación de la Casa de Misericordia, el denuncio de la corrupción de costumbres y del papel diabólico de las mujeres, de los excesos de las mismas mantuanas son reveladores de un nuevo y singular ambiente social. La utilización de fuentes complementarias permite al respecto confirmar la hipótesis según la cual las mentalidades fueron evolucionando a favor de un "control» social en la Caracas pre-independentista. Hay que "purgar la sociedad» declaran en 1792 los miembros del cabildo (32).

La propuesta formulada por el Gobernador José Carlos de Agüero, relativa a la creación, hecha realidad poco tiempo después, de los alcaldes de barrio se funda en la uextensión de la ciudad", que convierte a ésta en el refugio predilecto de los esclavos fugitivos, de los vagabundos y otros males. En 1799, la elección de los alcaldes de barrio, prevista para Caracas por un decreto real (RO de 13 de noviembre de 1778) tuvo como consecuencia una polémica, que desencadenó el origen étnico de uno de los elegidos, un zapatero, o sea un oficio incompatible con la distinción reivindicada por el interesado como lo indican los 16 firmantes de una petición dirigida al Capitán General. A los alcaldes de barrio sólo se les encargaba vigilar las posadas al anochecer, cuando indigentes y mendigos se acercaban a estas posadas o mesones, o también a las pulperías (denunciadas como lugares de perversión en 1815 ...), de administrar la justicia en el conjunto del barrio, pero esta situación les resultó «intolerable» a los otros elegidos, "nobles de nacimiento» o de privilegio que no

(31) ACM, Actas del Cabildo, fo 14: bando de 4 de enero de 1787. ACM, Cárceles, 1807-1846: el procurador al Capitán General, 10 de diciembre de 1807. Vicente Emparán al Ayuntamiento, 24 de mayo de 1809. Representación de los pulperos al Capitán General, 11 de septiembre de 1809. Decreto del 11 de julio de 1809; en diciembre, los pulperos apelaron ante la Audience esta decisión.

(32) ACM, Actas del Cabildo, 1791: fo 139 ss, junta del 22 de agosto de 1791: se alude también a la necesidad "de un puesto donde corregir con la autoridad de la justicia los esclavos y los sirvientes". Para una aproximación a esta ideología del trabajo y a la consecuente modificación del paisaje urbano, véase GEREMEK [30], pág. 275 . 
vacilaban en ostentar su pureza de sangre. De hecho, los cargos de alcaldes de barrio no tenían que recaer en "gente plebeya": elegir a unos pulperos o a los carniceros sólo le causaría «perjuicios enormes al orden político y civil» ... Ahora bien, el referido decreto sólo contemplaba aunque en términos significativos, la elección de

blancos honrados, nobles y plebeyos, europeos y criollos que no ejerzan oficios mecánicos ni sórdidos porque estos empleos se han de reputar como actos positivos y honoríficos de la República, que han de servir a las familias de los que los obtengan para pruebas, y otros casos de honor (33).

¿Prudencia o respeto de las tradiciones? En diciembre de 1801, fue Carlos Palacios, capitán retirado del batallón de milicias blancas de Caracas, alférez real y alcalde de barrio quien convocó las elecciones en el barrio de San Pablo. En 1803 figuran entre los alcaldes electos el Dr. José María Tovar, hijo de Martín Tovar. En 1809, Feliciano Palacios, regidor alférez y capitán de milicias de los valles de Aragua ocupa el cargo de alcalde del barrio de San Juan (34).

\section{CONCLUSIONES}

Más allá del interés manifestado por las élites locales por este aspecto de la res pública se afirma la voluntad de preservar intereses económicos, sociales y políticos, por no decir étnicos, ya limitados por las autoridades peninsulares de Caracas. En la mayoría de los textos consultados, se trata en efecto de reformar las costumbres de personas blancas, hombres y mujeres, ovejas descarriadas, mientras la cárcel se presenta como la solución más inmediata para los pardos. En cuanto a los esclavos, se especifica que los dueños de éstos tenían que mantenerlos cuando estaban encarcelados. Se trata por lo tanto de un interés, de una solicitud sumamente relativos de parte de las élites caraqueñas, lo que quizás pueda explicar las reticencias manifestadas en el

(33) Enrique Bernardo NúÑez, La ciudad de los techos rojos, Caracas, Monte Ávila, 1988, págs. 181 ss. ACM, Actas del Cabildo, 1779: fo 161 y ss. Actas de 1815: cabildo extraordinario, 2 de junio de 1815.

(34) ACM, Alcaldes de barrio, 1799-1810: representación de los alcaldes de barrio, Caracas, 2 de enero de 1799. 
particular por las autoridades religiosas, a pesar de la convergencia de los respectivos análisis (35).

No hay que olvidar sin embargo que las preocupaciones étnicas ostentadas por las élites se limitaban al caso de los vagabundos, como lo demuestra el temor de las mismas ante la promulgación de la famosa Cédula de Gracias al Sacar (1795) que iba a propiciar el "blanqueamiento" de los aspirantes a determinados oficios (artesanos) o ... al ingreso a la Universidad. Mucho antes de que se planteara este cambio «inacceptable», en 1788, el cabildo había examinado las pretensiones de los pardos: ingresar en las órdenes religiosas, contraer matrimonio con una persona blanca (por más que ésta pertenezca al estado llano); los cabildantes habían expresado el "horror" que les inspiraba semejante perspectiva (36). Tampoco hay que olvidar la coyuntura revolucionaria que perturba las conciencias y provoca el temor de los detentores del poder: en julio de 1797 se descubre la conspiración de Gual y España, y Picornell, inspirada de los ideales de la Revolución francesa. Mientras hasta los años 1780, la población carceral es la resultante de delitos menores en este sentido (robos, adulterios, crímenes diversos, abigeo...), en cambio en los años siguientes aparece el delito político. De ahí la apremiante necesidad, como lo subrayó el arzobispo Narciso Coll y Prat en 1812, de fundar el edificio social en "una educación cristiana, política, civil y social sólidamente combinadas, cual se requiere entre estas gentes tan diferentes en las clases, y colores, como en las habitudes, ocupaciones y fines, a que interiormente aspiran: desterrando tanta ociosidad, y vida mole, con precaver que las Ciudades no sean tan populosas y se vean más poblados los campos...» (37).

Si bien la preservación del orden público pasa por la reformación de las conciencias, la represión de las desviaciones, junto a la persecución de las «ideas perniciosas» está ya en el orden del día. No se excluyen por eso preocupaciones de índole escatológico: se estigmatiza la decadencia de las costumbres, la "relajación»

(35) Acerca de las controversias que originó en Europa la "nueva política social", de las prerrogativas de la Iglesia y de las aprehensiones divergentes de la noción de "bien público", véase GeREMEK [30], pág. 231.

(36) Una aproximación a esta temática figura en Ildefonso LEAL. [1]. ACM, Actas del Cabildo, 1796: una reunión del 26 de enero de 1796 recuerda, en el mismo orden de ideas, que se les prohibía ejereer la medicina a los mulatos. ACM, Actas del Cabildo, 1788, 1789: fo 149 ss. Reunión del 6 de octubre de 1788. En fo $47 \mathrm{v}^{\mathrm{o}}$ : junta ordinaria del 18 de mayo de 1789.

(37) Narciso Col. y PRAT, Memoriales sobre la Independencia de Venezuela, Caracas, Academia Nacional de la Historia, 1960, pág. 78. 
de las mismas, y los prelados no dejan de recordar el temblor de 1812, interpretado como un castigo divino por los pecados que se habían cometido anteriormente tanto desde el punto de vista espiritual como ... político (rechazo de la legítima autoridad de Fernando VII). En vísperas de la Independencia, en 1817, se persiguen a los "vagabundos que infestan la ciudad" pero también a los condenados por diversos motivos, las patrullas nocturnas se multiplican para evitar robos y saqueos pero las milicias - blancas - tiene como misión fundamental la de ayudarle al gobierno por lo que toca a la "seguridad general». Evolución que las ordenanzas municipales de 1820 retoman de manera significativa: la cuestión de los "verdaderos pobres" figura ahora junto a unos reglamentos de policía que poco les tienen que envidiar a sus equivalentes europeos del momento. A ese respecto, se puede considerar que el papel del indigente no consiste tanto en resaltar las virtudes ajenas, incluso haciendo acto de caridad. Son valores negativos los comportamientos de esta categoría social en vísperas de la Independencia. Si se sigue considerando a la pobreza como una enfermedad inherente a la sociedad misma, llega a ser característica de determinadas clases sociales, de la misma manera que la frontera entre el mendigo y el vagabundo sigue siendo indefinida.

La pobreza se impone sin embargo como una preocupación constante bajo varios aspectos. Constituye en este sentido una referencia explícita a lo que Geremek calificaba, al analizar el fenómeno del pauperismo, de paso de lo coyuntural a lo estructural. En esta perspectiva, es lógico que el mundo de la miseria y del crimen siga fascinando a las élites intelectuales y políticas, lo que reflejan sin lugar a dudas las actas del cabildo caraqueño u otros escritos de orientación política. Pero la visión que se tiene del pobre en la sociedad venezolana de fines de la Colonia refleja claramente las mutaciones que se estaban llevando a cabo en esta misma sociedad: la proporción creciente de los pobres, de personas incapaces de mantenerse por sí mismas, pone a prueba la doctrina tradicional - tal como la entendía la Iglesia- de la beneficiencia y de la asistencia a los pobres.

El crecimiento numérico de los vagabundos y de los mendigos no parece resultar aquí de un proceso de pauperización como fue el caso en varias ciudades grandes de la Europa moderna: se produce en ef ecto en un contexto de prosperidad generalizada al conjunto de la Provincia de Caracas. Confirma sin embargo que la reorganización de las instituciones hospitalarias, de la asistencia 
a los pobres y de las modalidades del control social se efectúan en el medio urbano siguiendo pautas acumulativas, en otros términos bajo la presión de las circunstancias y dejan por lo tanto testimonios duraderos de estas experiencias en el paisaje urbano (38).

(38) NúÑEz [33], pág. 213; Troconis [9], pág. 107; ACM, Actas del Cabildo, 1812, 1817, 1818: sesión del 5 de mayo de 1812, 2 de junio de 1817, 17 de febrero de 1817. GEREMEK [27] págs. 203 y ss. Del mismo autor [30] págs. 133, 203, 261 y: Les fils de Caïn. L'image des pauvres et des vagabonds dans la littérature européenne du XVe au XVIIle siècle, Paris, Flammarion, 1991, págs. 78, 249, 357, 361. 